\title{
O PAPEL DOS CRÍTICOS, REALIZADORES E AUDIÊNCIA NA CONFORMAÇÃO DE UMA TEMÁTICA E SEU GÊNERO: EM ANÁLISE O RECASAMENTO NA SÉRIE TELEVISIVA TUDO NOVO DE NOVO
}

\author{
Simone Maria Rocha ${ }^{1}$
}

\begin{abstract}
Resumo: A partir do pressuposto de uma necessária articulação entre os domínios da cultura e dos media, este artigo propõe discutir o papel dos discursos de críticos, realizadores e audiência na abordagem do tema do recasamento e do gênero série a partir de Tudo Novo de Novo, exibida pela Rede Globo de Televisão em 2009. Por entendermos gênero televisivo como uma mediação entre as práticas da produção, da crítica e da audiência (MARTÍN-BARBERO, 2001) adotaremos os princípios da análise cultural de gênero televisivo como proposta por Jason Mittell (2004). Nosso estudo alinha-se à perspectiva de Mittell segundo a qual práticas culturais são constitutivas das práticas midiáticas e gênero é visto como uma importante chave de leitura quando se trata de compreender os sentidos atribuídos a uma representação forjada pelos media.
\end{abstract}

Palavras-chave: crítica cultural, gênero televisivo, recasamento.

\begin{abstract}
The purpose of the present paper is to analyze the role of the discourses of critics, producers and audience in the approach to the theme of remarriage, and the genre of series, from the Brazilian series Tudo Novo de Novo, broadcasted by Rede Globo de Televisão in 2009. Our perspective assumes there is a necessary link between the fields of culture and media, and we perceive the various genres of television as a point of mediation between production, the critics and consumption practices (MARTÍNBARBERO, 2001). In this study, we will adopt the principles of cultural analysis of television genres, as proposed by Jason Mittell (2004), and focus on genres as an important element to understanding the meanings assigned to a media representation.
\end{abstract}

Keywords: cultural criticism, television genre, remarriage.

\section{Televisão e cultura: uma articulação necessária}

A nossa vida cultural nos é apresentada de várias formas. Dentre os discursos sociais disponíveis e que nos oferecem um modo de ver e conhecer aspectos de nossa realidade sócio-cultural, aqueles veiculados pela TV são fundamentais. A televisão é um meio cotidiano e doméstico que se configura tanto por sua presença constante nos diferentes lares quanto pelas circunstâncias dentro das quais ela é assistida. Alguns autores (ELLIS, 1992; FISKE e HARTLEY, 1978) afirmam que os programas de TV são endereçados a uma audiência

\footnotetext{
${ }^{1}$ Doutora em Comunicação e Cultura pela UFRJ com Pós-doutorado em Comunicação Social pela UFMG. Professora do Programa de Pós-Graduação em Comunicação Social da UFMG e coordenadora do Grupo dePesquisa Comunicação, Mídia e Cultura. Email: smarocha@ig.com.br.
} 
presumida que tem por base uma família nuclear "típica"2. Tais características que configuram o meio surgem a partir da mútua afetação entre discursos midiáticos e vida social, o que nos impede de pensar que as representações produzidas pelos media sejam desconectadas da realidade sensível. Seja pela domesticidade do aparelho seja pela significativa audiência que a televisão alcança, tal meio possibilita grande circulação de sentidos e representações que configuram e são configurados nas práticas culturais.

Dada a importância dessas práticas na configuração dos fazer televisivo, neste artigo gostaríamos de explorar as que envolvem os discursos de críticos, mas também de realizadores e audiência acerca de uma representação televisiva - que trata das dúvidas, conflitos e expectativas de quem procura construir uma nova relação através de um recasamento ${ }^{3}$ - e o gênero ao qual ela pertence. Nossa análise tomará como objeto empírico a Série Tudo Novo de Novo, exibida em 2009, às terças-feiras, por volta de 22h40minh, pela Rede Globo de Televisão.

\section{Estéticas da televisão}

A produção ficcional televisiva caracteriza-se por uma estética da repetição (MARTÍN-BAERBERO, 2001) e constitui-se a partir de dois tipos básicos: a série e a ficção seriada. Ambos os tipos implicam num modo específico de repetição cujo aperfeiçoamento vem acontecendo ao longo dos anos. No geral as ficções seriadas se constituem a partir de certa progressão narrativa que se encaminha para uma conclusão. Ao se estruturar dessa forma, elas multiplicam os incidentes no decorrer de sua exibição, mergulha seus personagens em diversas tramas e lida com uma gama complexa de relações e situações. Sua amplitude pode abarcar diferentes gerações e seu acompanhamento requer um conhecimento prévio acumulado, embora as instituições televisivas levem em conta que grande parte da audiência pode perder um ou outro capítulo, inclusive o primeiro que tem caráter expositivo ${ }^{4} \mathrm{~A}$

\footnotetext{
${ }^{2}$ Esta concepção é vista em comerciais, na interpretação de estatísticas feitas nos noticiários (para a 'média' das famílias isso quer dizer...), nas 'famílias' selecionadas para programas de jogos e brincadeiras, nas 'famílias' mostradas em representações ficcionais variadas. Contudo, Ellis chama atenção para o fato de que apenas uma minoria da população da Grã-Bretanha, por exemplo, vive de acordo com tal concepção. Já em 1992 a unidade familiar nuclear, do pai trabalhador, mãe dona de casa e crianças dependentes e em idade escolar respondiam por menos de 5\% da população, cf. Ellis 1992.

${ }^{3}$ Foge aos interesses deste artigo discutir se as uniões legais e as consensuais, ou seja, aquelas em que os parceiros co-habitam formando um novo casal, sem a existência de vínculos legais, são ou não consideradas casamento. Partimos do pressuposto de que a Série, ao ser divulgada como voltada para tal temática, trata, sim, das tentativas que as pessoas empreendem na busca de um recasamento.

${ }^{4}$ Para minimizar este aspecto várias técnicas são empregadas tais como a sequência do título que introduz personagens, a repetição de um fragmento final do capítulo anterior antes do início do próximo e referências precisas sobre eventos que são objeto da conversação dos personagens.
} 
construção seriada apresenta problemas para a televisão como, por exemplo, assegurar uma audiência constante para os exigentes patamares que a televisão requer ${ }^{5}$.

Já a série não é feita tendo em vista uma finalização e é estruturada em torno de uma situação particular e de um conjunto fixo de personagens, ainda que este núcleo possa contar com participações especiais. Em cada episódio há a recorrência a uma temática inicialmente estabelecida (a vida em família, a vida na favela, uma crise conjugal, a rotina de um hospital) em torno da qual os incidentes vão acontecendo de forma a serem solucionados no interior de cada um garantindo uma relativa independência em relação aos demais. A cada semana os personagens encontram-se em uma nova situação, embora seja possível identificar uma sequência lógica na exibição dos episódios. Por outro lado, é importante ressaltar que não há uma necessidade premente de que se assista a todos para que cada um seja compreendido em sua individualidade. Ainda assim, é inegável que o telespectador possa ter um ganho a mais quando lhe é possível acompanhar todos os episódios desde o início. As séries, então, estruturam-se sobre a repetição de uma problemática básica em torno da qual os episódios desenvolvem-se sem que isto implique numa resolução final.

Outra característica das narrativas televisivas diz respeito ao seu horário no fluxo de cada canal. Novelas, telejornais, séries e minisséries têm horários bem definidos o que contribui para o reconhecimento social dessas diversas narrativas. Muitas outras características ajudam-nos a definir o regime de representação da TV. Na próxima seção vamos nos dedicar àquela que se torna fundamental quando se trata de pensar representações televisivas a partir da mútua afetação entre televisão e cultura, qual seja, o gênero televisivo.

\section{O estudo do gênero como uma análise para além do texto: o papel de críticos, realizadores e audiência}

Os gêneros televisivos têm sido vistos tradicionalmente como uma faceta da programação - para entender uma telenovela, nós devemos analisar os exemplos mais representativos e importantes da história deste tipo de produção. A crítica especializada examina a função social de gêneros específicos, seja como veículo para expressar mensagens

\footnotetext{
${ }^{5}$ Boa parte da pesquisa sobre ficção televisiva seriada no Brasil dedica-se ao estudo das telenovelas e das minisséries. Destacamos o trabalho que vem sendo desenvolvido pela Rede de Pesquisa Obitel Brasil, ligado ao Observatório Ibero-Americano de Ficção Televisiva - um projeto que se articula em vários países em torno do estudo sistemático e comparativo das produções de ficção televisiva. O Obitel tem publicado vários trabalhos com resultados das pesquisas realizadas como o recente livro Ficção Televisiva no Brasil: temas e perspectivas, cf. Lopes (org) 2009.
} 
ideológicas seja como prática ritual para que os espectadores possam se sintonizar com programas que lhes interessam. Outras abordagens críticas consideram os gêneros numa perspectiva mais formal, na tentativa de definir características constitutivas de um caso em particular e de ilustrá-las com os elementos mais comuns criando vínculos entre diferentes programas. Tais abordagens, que focam no estudo de significados e formas de programação como um percurso para o entendimento de um gênero, podem ser consideradas como crítica textual.

Contudo, à medida que os estudos dos gêneros televisivos vêm crescendo dentro dos estudos dos media, os pesquisadores têm expandido seus métodos para além da crítica puramente textual. Vários deles (ALLEN, 1985; MARTÍN-BARBERO, 2001; MITTELL, 2004) têm investigado como o gênero funciona como parte de um sistema de produção e de consumo televisivo, explorando como práticas que envolvem a crítica cultural, a produção televisual e a audiência são parte do processo criativo e constitutivo de um gênero. Ao invés de considerá-los como propriedades dos programas televisivos a serem analisados, definidos ou interpretados, gêneros podem ser vistos como categorias culturais que circulam em torno e através da programação televisiva. Esta abordagem, influenciada pelo paradigma mais amplo da teoria pós-estruturalista, sugere um modo diferente de se entender a importância e a função cultural dos gêneros - no qual se evidencia a relevância das práticas de crítica e de consumo levando-nos a um caminho distinto que pesquisa a história dos gêneros televisivos através da análise do discurso (MITTELL, 2004).

De acordo com esta abordagem, gêneros não estão alojados nos textos ou em programas classificados por gêneros em particular; ao invés disso, eles são forjados pelo próprio processo de categorização cultural. Gêneros são categorias conceituais que agrupam programas televisivos e que articulam concepções culturais que vão além do próprio programa. Essas categorias são forjadas por uma ampla gama de práticas culturais que se somam aos discursos dos gêneros televisivos, desde comentários críticos, vinhetas, sites produzidos por fãs até regulações governamentais. Jason Mittell identifica três práticas discursivas em particular que são comumente usadas para constituir os gêneros televisivos: definição (por exemplo, "este programa é uma novela porque conta uma história de amor cheia de encontros e desencontros"), interpretação (“minha vida é uma novela!") e avaliação (“as minisséries são mais bem produzidas do que as novelas”). Através destas práticas discursivas a categoria das telenovelas torna-se culturalmente coerente e acumula sentidos e associações que as vinculam a normas e valores sociais específicos, aspectos do gênero que não poderiam ser discerníveis quando analisamos os programas em si. 
Sendo assim, ao invés de examinarmos a evolução dos sentidos das séries policiais analisando os programas identificados sob esse gênero, nós podemos examinar como a crítica cultural, a indústria e a audiência televisiva produzem sentido da categoria das séries policiais através dos diferentes contextos históricos e sociais. Nós podemos levar em conta se as séries policiais são entendidas como críticas ou apoiadoras das normas sociais dominantes, se elas são vistas como conectadas com os casos da vida real ou se elas funcionam como fantasias escapistas, ou se o gênero é considerado como uma forma cultural valorizada ou descartada como ruim ou violenta. Todos os sentidos das séries policiais são relevantes dentro de contextos e momentos históricos diferentes. Tal pesquisa requer a análise de uma ampla gama de opiniões da crítica, da audiência, dos realizadores e dos representantes institucionais sobre o uso de categorias genéricas, além do mapeamento das mudanças nos discursos acerca de uma categoria em particular em diferentes contextos históricos. É o que Mittell denomina “genealogia genérica", partindo da concepção de formações discursivas de Foucault ${ }^{6}$.

Esta abordagem que propõe estudar os gêneros televisivos como categoria cultural adota um percurso que vai 'de baixo para cima' na constituição de um dado corpus de um gênero - ao invés de uma tentativa crítica de definir claramente os limites ou parâmetros de um gênero, nós podemos olhar para a circulação cultural de definições para entender como um dado texto é categorizado ou como pode haver definições de gênero que competem entre si e que sugerem uma variação de concepções e valores culturais. Como Mittell afirma (2004, pág.14):

Nosso objetivo ao analisar os discursos genéricos não é alcançar uma definição, uma interpretação e uma avaliação "próprias" de um gênero, mas explorar as formas materiais em que uma configuração genérica recebe contribuições das práticas culturais nas quais ela opera. Quando o objetivo é entender gêneros como categoria cultural, o exame dos discursos que constituem tal categoria torna-se fundamental, pois isso nos ajuda a compreender como os gêneros funcionam dentro de contextos históricos, como eles envolvem e emergem, ou se encaixam em amplas relações de poder. Assim, pela mudança de foco que se distancia de projetos que tentam oferecer uma definição definitiva de um gênero, nós podemos olhar na direção dos modos nos quais as definições, interpretações e avaliações de gênero são parte de uma operação genérica culturalmente mais ampla. Ao

\footnotetext{
${ }^{6} \mathrm{~A}$ concepção de formações discursivas de Foucault parece particularmente apta a análise genérica. Foucault analisa amplas formações discursivas como sexualidade, insanidade e criminalidade, argumentando que elas são sistemas de pensamento historicamente específicos, categorias conceituais que funcionam para definir experiências da cultura dentro de um amplo sistema de poder. Essas formações discursivas emergem não de uma estrutura centralizada ou de um lugar único de poder, mas são construídas da base para micro instâncias. Embora as formações discursivas sejam sempre marcadas pelas descontinuidades, elas seguem regularidades gerais, se adequando aos amplos 'regimes de verdade' de uma sociedade. Finalmente, formações discursivas frequentemente parecem ser naturais ou propriedades internas dos seres, como se fossem humanas, mas são de fato culturalmente constituídas e variáveis.
} 
invés de questões tais como "o que uma série policial?" ou "como nós definimos o quiz show?" nós devemos olhar para as práticas culturais de interpretação e definição de gêneros difundidas que nos levem a questões tais como "o que os talk shows significam para uma comunidade específica?" ou "como a definição de animação é articulada por grupos situados socialmente?".

O estudo do gênero como categoria cultural oferece uma perspectiva diferente daquela mais comum da crítica textual, pois expande o exame para além do espaço da programação televisiva e dá a ver a relevância das opiniões de críticos e especialistas, além de outros, no processo de circulação e definição genérica e, em última medida, as relações entre televisão e vida cultural. Quando as análises discursiva e textual trabalham juntas, nós podemos compreender melhor como os gêneros operam tanto em torno quanto dentro da referida programação. Tal abordagem chama a atenção para os lugares e modos de práticas genéricas que auxiliam no entendimento de como as categorias da programação televisiva tanto definem quanto são definidas por contextos culturais e práticas discursivas.

É essa abordagem teórico-metodológica que sustenta o estudo aqui proposto. Nossa busca pelo entendimento de como a série Tudo Novo de Novo apresenta o tema do recasamento passa pelos diferentes discursos proferidos por críticos especializados, membros da audiência, realizadores e demais atores ligados à instituição televisiva. Nessa medida pretendemos evidenciar de modo mais específico o papel da crítica cultural tanto no modo de interpretar a abordagem do tema quanto no processo de definição do gênero.

\section{O objeto da análise}

Antes de falar do tema e da série Tudo Novo de Novo, objeto de análise deste artigo, é preciso situá-la dentro do corpus mais amplo de nossa pesquisa (Rocha 2009-2011) no qual procuramos englobar um conjunto de produções que tiveram seu início no final dos anos 70 e ficou conhecido como Séries Brasileiras. Nosso interesse foi o de averiguar em que medida este sub-gênero (do gênero série) constitui-se num catalisador cultural que abre espaço no fluxo televisivo para discutir questões candentes na sociedade contemporânea ao seu momento de produção. A questão norteadora dessa pesquisa foi: qual o lugar cultural das Séries Brasileiras no fluxo televisivo?

Séries Brasileiras foi o nome dado a um projeto de 1979 da TV Globo, proposto por José Bonifácio de Oliveira Sobrinho, cuja finalidade era explorar o universo do Brasil contemporâneo. Daniel Filho (2001), responsável pela produção do projeto, explica que até 
então as séries de TV produzidas no Brasil eram enlatados dos similares estadunidenses ${ }^{7}$ e que era o momento de construir uma alternativa de programação, tendo como propósito a criação de um produto nacional que concorresse ou dividisse um mercado já ocupado pelo produto similar estrangeiro. Para o Diretor:

As séries propõem uma diversificação da programação. Elas não pretendem substituir qualquer outro gênero. Simplesmente surgem como coisa nova para a televisão brasileira, pois já existem em termos americanos. Então é o abrasileiramento do gênero. ( ...) $\mathrm{O}$ que defendemos é a troca de informações. Mas, para isso, temos de fazer seriados, como já fizemos novelas, musicais (...) As novelas de uns dez anos para cá, ficaram, praticamente, como donas da televisão. Agora surge a possibilidade de ampliar isso ${ }^{8}$.

O objetivo do projeto era produzir séries que tivessem a cara do país: "A gente não podia fazer uma simples cópia ou uma simples tradução dos americanos, queríamos cair na realidade brasileira. E daí nasceram Plantão de Polícia, Carga Pesada e Malu Mulher" (FILHO, 2001, p. 59). Plantão de Polícia e Carga Pesada tematizavam as problemáticas dos "brasis" urbano e rural, respectivamente. Já a personagem principal de Malu Mulher vai além da previsibilidade do familiar happy-end para lidar com uma variada gama de questões, dúvidas e demandas do gênero feminino que começaram a fervilhar em muitos lugares desde os anos sessenta. O final dos anos 70 e as mudanças conjunturais que aí se iniciavam, além dos novos universos simbólicos que se formavam, viabilizaram esses projetos ficcionais televisivos, como observa Daniel Filho “...acho que o seriado é, também, um produto da abertura proposta pelo país, na medida em que teremos chance de mergulhar mais fundo na nossa realidade" $"$.

Através da pesquisa foi possível perceber que, se por um lado, a proposta dessas produções tinha objetivos fundamentalmente mercadológicos, por outro, poderíamos entender que, por se anunciarem como primeira temporada ou se tratarem de um programa piloto, essas Séries problematizaram, tensionaram e representaram, de maneira ampliada e diversificada,

\footnotetext{
${ }^{7}$ A primeira série de TV produzida no Brasil foi "Vigilante rodoviário", exibida pela TV Tupi a partir de 1961 (SOBRINHO, 2001). A série narrava as aventuras do inspetor Carlos e seu cachorro Lobo contra o crime, em uma trama policial. Até então, as séries eram transmitidas ao vivo, como foi o caso de "Sítio do Picapau Amarelo, de 1952, e "Alô Doçura", de 1953, (ambas produzidas pela TV Tupi), e de "Capitão 7", de 1954, produzida pela TV Record. Na TV Globo, o primeiro seriado produzido foi "Rua da Matriz", de 1965, baseado no programa inglês "Coronation Street". Até o projeto das Séries Brasileiras, a Globo não investiu muito em produções deste gênero, estando mais voltada para as telenovelas.

${ }^{8}$ Material de divulgação das séries da Globo citado por: PEREIRA, Carlos Alberto Messeder e MIRANDA, Ricardo. Televisão, o nacional e o popular na cultura brasileira. São Paulo, Brasiliense, 1983, p.60-65.

${ }^{9}$ Note-se que neste momento inicial de criação e mesmo em momentos posteriores como o da publicação do Dicionário da TV Globo não se identifica a preocupação de uma distinção mais precisa entre seriado e série como a que estamos tentando imprimir neste trabalho.
} 
temas contemporâneos à sua época de exibição, de forma recorrente, desde os anos 1970. As possibilidades deste sub-gênero foram feitas notar pelo próprio Daniel Filho ao afirmar que “... no seriado cada episódio é fechado em si mesmo, nasce a oportunidade de se dar um tratamento não romântico, o que a novela não permite devido a seu gênero e forma"10 ${ }^{\text {. }}$

Após as devidas caracterizações e recortes, o corpus ficou assim constituído:

\begin{tabular}{|l|l|l|}
\hline Plantão de polícia $(1979-1981)$ & Carga Pesada $(1979-1981)$ & Malu Mulher $(1979-1980)$ \\
\hline Amizade colorida (1981) & Obrigado, doutor $(1981)$ & Delegacia de mulheres $(1990)$ \\
\hline Mulher $(1998-1999)$ & Cidade dos homens $(2002$ / 2005) & Carandiru (2005) \\
\hline Antônia $(2006 / 2007)$ & Tudo novo de novo (2009) & Força tarefa $(2009$ / 2010) \\
\hline
\end{tabular}

Obviamente este corpus não incluiu todas as produções comumente englobadas no gênero série, pois nossa intenção foi evidenciar como suas características, criadas a partir do projeto Séries Brasileiras, permitiu-nos identificá-lo como sub-gênero, tendo em vista suas marcas próprias (força da temática, o horário de exibição e a contemporaneidade do tema em relação ao seu período de produção). Se do ponto de vista geral, este corpus guardou similaridades com as demais séries, de um ponto de vista específico foi possível perceber a composição de um conjunto em virtude de suas particularidades. Daí a nomeação de Séries Brasileiras para esse sub-gênero em função da matriz que o identificava.

Tudo novo de novo foi uma Série produzida e exibida pela TV Globo, às sextas-feiras, por volta das 22:40h, em 2009 num total de 12 episódios. Escrita por Lícia Manzo, a Série mostrava os encontros e desencontros da arquiteta Clara (Júlia Lemmertz) e do engenheiro Miguel (Marco Ricca) na tentativa de construir uma nova relação num contexto onde Clara já tinha dois filhos, de dois casamentos anteriores, e Miguel tinha uma filha, da primeira esposa. O programa narrou várias dificuldades comuns a homens e mulheres contemporâneos que tentam ficar juntos unindo suas famílias num recasamento. O modo como a temática foi abordada abriu espaço para as dificuldades cotidianas enfrentadas pelo novo casal, como falta

\footnotetext{
${ }^{10}$ Isso difere de outros gêneros televisivos como a telenovela. Com um longo histórico de exibição na televisão aberta a matriz melodramática é característica definidora deste gênero em seus mais diferentes formatos - novela das seis, das sete, das oito. Há um reconhecimento social desta estrutura narrativa e, portanto, uma expectativa de assistência por parte da audiência. Muitas das vezes em que se procurou inovar a tentativa mostrou-se frustrada em virtude da rejeição dos telespectadores percebida através dos baixos índices de audiência. Um exemplo foi o da novela das 19 horas da Rede Globo, Tempos Modernos, exibida em 2010. Em entrevista ao site IG em 26 de abril de 2010, a atriz Grazi Massafera, que compôs o elenco do folhetim, falou sobre a 'baixa audiência em Tempos Modernos'. Segundo a atriz: "A novela está mudando muito. No início a proposta era diferente, não tinha conflito, mas o público não aceitou...". Também Aguinaldo Silva, supervisor de texto, se pronunciou a respeito em um evento no Rio de Janeiro: "Não me sinto responsável pelo sucesso ou insucesso da novela. Foi uma tentativa de inovação, mas novela tem que ser novela, não dá para mexer na linguagem de folhetim". Disponível em http://extra.globo.com/blogs/telinha, consultado em 27/04/10.
} 
de tempo, intromissões familiares, rejeição do (a) parceiro (a) por parte dos filhos, problemas na escola, problemas com ex-cônjuges, etc.

A proposta foi mostrar os desafios da família brasileira contemporânea a partir de uma ótica leve e bem humorada, o que foi feito notar nas inúmeras confusões e desentendimentos que envolvem tanto Clara e Miguel quanto seus amigos e familiares, pois, no caso da arquiteta, havia a convivência com seus dois ex-maridos, Fred e Paulo, com a ex-enteada Bia, com a irmã Nanda, com os pais que, após anos de casamento se separaram e arranjaram novos namorados, e com a babá Salete. Nas relações do engenheiro estavam envolvidos a exmulher, a atual namorada, o sócio e cunhado e a irmã. Além desses, tanto Clara quanto Miguel compartilhavam dos problemas pessoais de um casal de clientes/amigos que se encontravam numa situação complicada já que ele, pai de quatro filhos, não pretendia mais têlos e ela sonhava em ser mãe pela primeira vez.

Fiel às características culturais do gênero série, como a problematização de diversas dimensões de um tema central - o recasamento (como a rejeição do parceiro por parte dos filhos, a dificuldade de conciliar agendas, problemas com os ex-companheiros etc) - e a de servir de porta de entrada para discussões de temas contemporâneos à época de sua produção, Tudo novo de novo contava a cada episódio, além do elenco fixo, com participações especiais de vários atores.

\section{Os procedimentos da pesquisa}

O confronto com o objeto e a questão a ser tratada neste artigo nos conduziu na busca por possíveis explicações que nos auxiliassem na compreensão de como a crítica cultural entendeu o modo como a temática do recasamento foi tratada em Tudo novo de novo. Seguindo os princípios da análise de gênero televisivo como categoria cultural, partimos em busca de enunciações, proferidas pelos vários atores sociais envolvidos nesse processo de produção e consumo televisivo, identificadas em discursos de definição, avaliação e interpretação em torno da Série (MITTELL, 2004). Para evidenciar os distintos papeis essa busca tomou por base opiniões e entrevistas publicadas em sites e materiais institucionais da Rede Globo e demais sites de críticos aí hospedados; matérias, críticas e entrevistas veiculadas nos media; opiniões postados em blogs; e, eventualmente, artigos acadêmicos.

Consideramos discursos de definição as enunciações provenientes do grupo de realizadores (atores, diretores, emissora) envolvidos na produção da Série com o objetivo de categorizá-la. Ou seja, proferimentos que buscassem responder a pergunta "Sobre o que é 
Tudo novo de novo?". Como discursos de interpretação, consideramos enunciações que trouxessem categorizações, sobretudo por parte da crítica especializada e, eventualmente, por parte da audiência, que mapeassem sentidos atribuídos à série. Finalmente, como discursos de avaliação, consideramos as enunciações que buscassem atribuir valor cultural ao produto televisivo, classificando-a em parâmetros de qualidade. Juntos, discursos de interpretação e avaliação, compõem a sua crítica cultural ${ }^{11}$.

\section{O papel da crítica cultural na abordagem do recasamento em Tudo Novo de Novo}

A literatura que trata do recasamento é relativamente escassa. A área da Psicologia é uma das poucas que tem investido no tema, pois, segundo Travis (2003) muitos problemas que envolviam casais recasados e novos arranjos familiares não estavam sendo bem encaminhados porque a psicoterapia era baseada mais na experiência clínica com famílias de primeiro casamento (as chamadas famílias nucleares) e em premissas do senso comum, do que em discussões e estudos específicos relacionados ao tema. De todo modo, segundo a autora, tem sido possível perceber desenvolvimento e continuidade no estudo do tema.

Os dados dos institutos de pesquisa também não contemplam a gama de possibilidades que o recasamento pode significar. Segundo dados do IBGE (1994) sobre casamentos, separações e recasamentos, $15 \%$ dos casamentos realizados na cidade do Rio de Janeiro, por exemplo, são, na realidade, recasamentos. Na prática um número significativo de recasamentos acontece de modo consensual, sem o envolvimento de contrato ou qualquer procedimento legal. Nesse sentido, podemos concluir que o número de recasamentos é consideravelmente maior do que o apontado pelas pesquisas oficiais.

No que tange ao discurso midiático, do ponto de vista da produção, como já argumentamos acima, a audiência presumida ainda é aquela que retrata uma família nuclear: pai, mãe e dois filhos em idade escolar. A escassez de produtos e de estudos de mídia sobre a temática dificulta o entendimento da questão neste ambiente da vida social. Ainda que possamos nos deparar com famílias recasadas e diferentes arranjos familiares em telenovelas,

\footnotetext{
${ }^{11}$ Embora na proposta analítica de Mittell todos os atores sociais colaborem na construção cultural de um gênero e por isso proferem discursos de definição, interpretação e avaliação, metodologicamente tal proposta se mostra de difícil execução. A primeira dificuldade diz respeito ao caráter aleatório e desordenado da aparição desses discursos e da dificuldade de organizar diferentes enunciações no interior de uma mesma categoria discursiva. No caso especifico do corpus dessa pesquisa houve, também, dificuldades de ordem material, ou seja, a escassez de discursos específicos sobre as séries. Além do mais para melhor contemplar o problema que expusemos aqui, tal distinção confere maior evidência ao papel da crítica na configuração do tema e do gênero.
} 
por exemplo, a temática não ocupa espaço suficientemente significativo que dê margem a reflexões. Por isso a relevância de angariar as diferentes enunciações - de críticos, realizadores e audiência - acerca da abordagem feita na Série, objeto desta pesquisa.

A definição de que a Série foi o retrato da vida contemporânea aparece de modo claro na opinião dos realizadores. No DVD comercializado pela Globo Marcas somos informados de que

A arquiteta Clara é mãe de Carol e Léo, cada um de um (ex) marido. Já o engenheiro Miguel é um homem recém-separado e muito ligado à filha, a adolescente Júlia. A aproximação entre os dois e seus encontros e desencontros são o ponto de partida de Tudo Novo de Novo, uma série repleta de construções e desconstruções, que retrata a vida contemporânea onde dúvidas, perspectivas, medos e alegrias são constantes para quem busca o "recasamento" 12 .

Em muitas das enunciações encontradas e que se encaixam em discursos de definição este parece ter sido o traço mais marcante do produto: uma Série que falou do seu tempo, do que a sociedade vivia e definia como sendo suas características próprias. E por isso a temática apareceu com inegável força como na crítica a seguir:

\section{Novo e de novo}

Tudo novo de novo é o título definitivo do seriado que vai estrear na Globo em abril. O programa, do núcleo de Denise Saraceni, é sobre famílias reconstruídas. ${ }^{13}$

O recasamento foi tratado como algo que já faz parte das relações contemporâneas e o se que problematizou foram as dificuldades e percalços enfrentados e a esperança na construção de uma nova história de amor. Por isso, o recasamento foi o ponto de partida. Para Denise Saraceni, diretora:

A história se passa no Rio de Janeiro, mas poderia acontecer em qualquer lugar. Ela tem um olhar esperançoso sobre as relações humanas, mesmo quando desestruturadas. Aliás, é na desordem que encontramos a ordem. ${ }^{14}$

Para Lícia Manzo, roterirista:

Antes, o divórcio era a transgressão; hoje é praticamente a regra. Não dá para negar como as transformações familiares mudam o ser humano (...). ${ }^{15}$

\footnotetext{
${ }^{12}$ Trecho retirado da capa DVD da Série Tudo Novo de Novo. DVD Tudo Novo de Novo. Uma produção da TV Globo, realização Central Globo de Produção, Direção Geral Denise Saraceni, 0526-9 2010 ๑) TV GLOBO LTDA.

${ }^{13} \mathrm{http}: / /$ thiagocalypso.musicblog.com.br/136168/Grazi-foi-o-maior-Negocio-da-China-sera/ patriciakogut.com. Em 25.04.2011).

${ }^{14} \mathrm{http} / / /$ www.logado.info/seriados/conheca-o-seriado-tudo-novo-de-novo-da-globo. Em 26.04.2011.

${ }^{15} \mathrm{http}: / /$ privusbrasil.blogspot.com/2010/06/tudo-novo-de-novo-agora-em-dvd.html. Em 25.04.2011.
} 
Embora os vários discursos de definição certificassem que a Série tratou sim de um retrato da sociedade, não houve preocupação premente em se fazer ressalvas como a de que, embora a série fosse um produto televisivo e que, portanto, dialogasse necessariamente com a sociedade de seu tempo, ele o fizesse segundo modos operatórios próprios do fazer deste medium. Isso pode ser visto, por exemplo, através do fato de que em poucos episódios fez-se uma menção pouco aprofundada no que concernia às dificuldades financeiras. E bem sabemos que esta é uma questão que permeia a maioria dos casamentos desfeitos e das famílias recasadas. $\mathrm{O}$ casal em questão era composto por profissionais liberais - arquiteta e engenheiro - que pareciam bem resolvidos profissionalmente. As casas em que moravam eram bem estruturadas, mobiliadas e em bairros bem localizados, os filhos estudavam em escolas particulares, Miguel sempre socorria a ex-mulher nos descontroles financeiros etc. Ainda assim, a mútua afetação entre televisão e cultura foi feita notar na interpretação dos críticos:

\section{Grupo de pesquisa aprova seriado}

Aconteceu em São Paulo o grupo de discussão de "Tudo novo de novo", seriado da Globo (...). Os entrevistados — dez grupos de homens e mulheres de idades e classes sociais diferentes — falaram bem da produção.

..e mais

Independentemente da classe social ou idade, todos os entrevistados da pesquisa admitiram "se reconhecer" em "Tudo novo de novo"16.

E até mesmo os realizadores procuraram interpretá-la segundo essa proposta da identificação da audiência com as diversas situações e posições de sujeito oferecidas pelo programa. Para a diretora Denise Saraceni:

São situações reais, questões que discutimos e vivemos no dia a dia. Por isso, o telespectador se identifica muito ${ }^{17}$.

Não obstante os conflitos, as dificuldades no estabelecimento de fronteiras que distinguem a nova família das relações familiares de casamentos anteriores, na questão disciplinar, na atribuição de responsabilidades financeiras, na relação entre enteados, meioirmãos, etc, o programa criou oportunidades para o entendimento e a aceitação de diferentes regras de funcionamento familiar, além da noção de que a família recasada não constitui um

\footnotetext{
${ }_{17}^{16}$ patriciakogut.com publicado em 28.08.2009 e consultado em 25.04.2011.

${ }^{17} \mathrm{http} / / /$ tvcontacto.wordpress.com/2010/06/29/\%E2\%80\%9Ctudo-novo-de-novo\%E2\%80\%9D-agora-pode-serencontrado-em-dvd/ e consultado em 25.04.2011.
} 
problema em si e que pode, até mesmo, representar transformações importantes na integração e nas interações familiares. Segundo uma telespectadora

Gosto do programa tudo novo de novo, me ajuda a entender separação, e ter outro relacionamento $^{18}$

Mas, nem todos os discursos de interpretação apontaram os méritos da produção. Dentro os discursos da crítica existiram aqueles que não a consideraram como uma contribuição a esta temática que, em nosso entendimento, ainda é pouco explorada na TV. Segundo a opinião de alguns críticos:

(...) trata-se de uma família como quase todas as que conhecemos. Pai e mãe são separados, há filhos de vários casamentos, conflitos inevitáveis, e a vontade de acertar de quem encontra um novo amor e não quer - ou acha que já não tem o direito - repetir erros. A história de Lícia Manzo retrata as vicissitudes do cotidiano de um casal banal.

A pergunta inevitável: o que é novo nisso tudo? Praticamente nada. Famílias recompostas e mulheres que têm mil braços para abraçar inúmeras tarefas profissionais e domésticas são figuras corriqueiras, não é de hoje. Já nos anos 70, grande parte das famílias tinha este desenho. Ainda assim, se o título "Tudo novo de novo" faz promessas falsas, o que se vê ali é bem verdadeiro $^{19}$

Podemos argumentar que a questão não é que diferentes arranjos familiares e famílias recasadas fossem novidade, mas sim o modo como figuraram como temática central de uma produção televisiva feita nos moldes das Séries Brasileiras, ou seja, com possibilidades de aprofundamento das diversas dimensões do tema, com os desafios que atravessavam as relações contemporâneas, e com espaços iguais para homens e mulheres reconstruíssem suas vidas ao lado de novos parceiros - como Clara e Miguel. O programa chamou a atenção para o fato de que com o recasamento também começa uma nova família sem a possibilidade de que esta seja construída gradualmente. O casal recasado tem que investir na relação a dois e, ao mesmo tempo, criar condições para a adaptação de uma vida comum, pois os filhos de casamentos anteriores, em fases diferentes ou não, já existem e exigem atenção, orientação e cuidados.

Já nos discursos de avaliação que procuraram atribuir valor cultural à Série, esta parece ser tida como uma produção que mereceu destaque no que foi produzido pela Emissora naquele ano. É o que constatamos na crítica a seguir:

\footnotetext{
${ }^{18}$ http://oglobo.globo.com/cultura/kogut/posts/2009/06/14/195590.asp e consultado em 28.04.2011.

${ }^{19} \mathrm{http}: / /$ fucandoatv.webnode.com/news/\%E2\% $\% 0 \% 98$ tudo\%20novo\%20de\%20novo\%E2\%80\%99\%3A\%20e\%2 0bom, \%20mas\%20de\%20novo\%20n\%C3\%A3o\%20tem\%20nada\%20/. Consultado em 26.04.2011
} 
Trata-se de um programa bem-feito que emociona seja pela direção competente de Denise Saraceni (nenhuma surpresa), seja pelo elenco. Júlia Lemmertz, atriz madura, mostra o talento e as rugas, sem medo, com entrega e sinceridade. Só o trabalho dela já seria motivo suficiente para o público conferir o seriado. Mas há ainda Marco Ricca, também com total domínio de cena. Entre as crianças, Poliana Aleixo (Júlia) e Daniela Piepszyk (Carol) são dois achados, com interpretações excelentes, longe do modelo treinadinho que se costuma ver na TV. ${ }^{20}$

Como já assinalamos, entendemos por discursos de avaliação aquelas enunciações que buscassem atribuir valor cultural ao produto televisivo, classificando-o em parâmetros de qualidade. Nesse sentido, Tudo novo de novo tem servido, inclusive, para estabelecer esses parâmetros relativos ao que seria desejável ver e não ver na produção televisiva.

Estou muito triste em saber da não continuidade da série "Tudo novo de novo". Cada episódio retrata um pouco da vida real com situações que provavelmente todos nós já passamos. Tenho esperado toda sexta para assistir e sempre fico ansiosa pelo próximo encontro. Fica claro e evidente que cenas de sexo, violência e corrupção geram mais lucros para a tv aberta. Vamos postar mais comentários em diversos sites para que ao menos saibam de nossa indignação. ${ }^{21}$

E tais discursos avaliativos apontaram não apenas a qualidade do programa como um todo, elogiando sua capacidade de dialogar com a situação atual das famílias brasileiras considerando-o como "real" - como apontaram, também, qualidades técnicas relativas a elenco, direção, roteiro etc:

Nota 10 para Tudo novo de novo. Muito bom e retrato de muitas famílias brasileiras $^{22}$.

Nota 10 para o Programa Tudo Novo de Novo, excelente texto, muito real, a química entre o casal clara e miguel também está maravilhosa, sem falar nos diversos conflitos que a trama aborda. Muito bom há tempos não fico a semana inteira esperando para assistir um programa. Bola dentro Globo! ${ }^{23}$

O programa pode não ter trazido grandes novidades para a TV, mas conseguiu a atenção do público porque é muito bem feito e tem elenco de primeira $^{24}$

\footnotetext{
${ }^{20}$ http://fucandoatv.webnode.com/news/\%E2\%80\%98tudo\%20novo\%20de\%20novo\%E2\%80\%99\%3A\%20e\%2 0bom, \%20mas\%20de\%20novo\%20n\%C3\%A3o\%20tem\%20nada\%20/ e consultado em 28.04.2011.

${ }^{21} \mathrm{http}: / / \mathrm{www} . \log$ ado.info/seriados/conheca-o-seriado-tudo-novo-de-novo-da-globo. Em 26.04.2011).

${ }^{22} \mathrm{http} / / /$ oglobo.globo.com/cultura/kogut/posts/2009/05/29/190893.asp e consultado em 25.04.2011).

${ }^{23} \mathrm{http} / / /$ oglobo.globo.com/cultura/kogut/posts/2009/06/14/195375.asp e consultado em 28.04.2011)

${ }^{24} \mathrm{http}: / /$ oglobo.globo.com/cultura/kogut/posts/2009/06/20/196846.asp e consultado em 28.04.2011).
} 
Em nossa própria avaliação, a abordagem aprofundada feita em cada episódio, a escolha por tratar da temática no gênero série (em virtude de suas características definidas a partir da relação produção e consumo de produtos televisivos e das expectativas que elas criam nos telespectadores), os termos utilizados para descrever as relações familiares criadas pelo recasamento (madrasta, padrasto e enteados), a representação do aumento das dificuldades que os membros da família sentiram para conviver com tais relações nos pareceram afinadas com o propósito de evidenciar como uma nova família lida com as complexas relações adquiridas através do recasamento.

\section{Conclusão: crítica de gênero é crítica cultural}

Os significados culturais contidos nas histórias narradas pela televisão são importantes, pois estão correlacionados ao contexto cultural situado além da tela. A tarefa mais desafiadora para a crítica de gênero é abordar essas correlações adequadamente. Em última instância crítica de gênero é crítica cultural.

Este artigo abordou uma teoria de gênero específica e argumentou sobre a importância do mesmo na organização das práticas televisuais. Na perspectiva aqui adotada, gênero televisivo é mais bem entendido como um processo de categorização que não é encontrado dentro dos textos, mas opera de modo a interrelacionar os domínios culturais da crítica cultural, das indústrias midiáticas, das políticas culturais e das audiências. Trata-se, portanto, de um circuito de prática cultural que opera em múltiplos lugares, ao invés de um domínio singular da crítica textual ou análise institucional. Nosso objetivo aqui foi o de evidenciar o papel que os críticos jogam nesse processo de configuração genérica, sem desconsiderar a contribuição que as demais dimensões oferecem.

Através da crítica tanto da temática quanto do gênero no qual ela foi trabalhada, nós pudemos vê-lo como modo chave que classifica e organiza nossas experiências midiáticas dentro de categorias que têm vínculos específicos com conceitos tais como valor cultural, audiência presumida e função social. Como a crítica nos ajuda a ver o gênero como uma prática multifacetada e em andamento, nós podemos concluir que as distinções e categorias de gênero operam como um processo ativo que envolve e constitui as políticas culturais e apontam como os media estão engajados na e definem a nossa cultura.

A partir da perspectiva culturalista, na qual a discursividade social é parte constituinte dos produtos midiáticos, é possível afirmar que a ficção televisiva configura e oferece material valioso para que os telespectadores possam compreender e fazer sentido da cultura e 
da sociedade a qual ele expressa. No caso específico de Tudo novo de novo foi possível visualizar as novas relações criadas pelo recasamento potencialmente conflituosas, complexas e ambíguas retratadas em situações tais como a da convivência com filhos de uniões anteriores, dos ciúmes, dos problemas com finanças e do relacionamento com os ex-cônjuges. Interessante notar que o recasamento, como demonstrado nas enunciações feitas pela crítica cultural, na maioria das vezes, vai "acontecendo", e isso é relevante de se assinalar, pois tal fato confere oportunidades para que casais, que vivem a experiência sensível de investir na construção de uma nova família, possam fazê-lo ainda que sem ter a clareza de um padrão ou de um conjunto de convenções estáveis e acordados socialmente.

\section{Referências Bibliográficas}

ALLEN, R. Speaking of Soap Operas. Chapel Hill : University of North Carolina Press, 1985.

ELLIS, J. Visible fictions - Cinema: television: video. London and New York: Routledge, 1992.

Ficção Televisiva no Brasil: temas e perspectivas. Maria Immacolata Vassallo de Lopes (org). SP: Globo, 2009.

FILHO, Daniel. O Circo Eletrônico - Fazendo Tv no Brasil. RJ: Editora Jorge Zahar, 2001.

FISKE, J. \& HARTLEY, J. Reading television. London: Methuen, 1978.

MARTIN-BARBERO, J. Dos meios às mediações. RJ: Editora UFRJ, 2001.

MITTELL, J. Genre and television. London and New York: Routledge, 2004.

ROCHA, S, M. Comunicação e cultura: perspectivas críticas e analíticas. Projeto de pesquisa apresentado ao CNPq para o biênio 2009-2011.

TRAVIS, S. Construções familiares: um estudo sobre a clínica do recasamento. RJ p. Tese de Doutorado - Departamento de Psicologia, Pontifícia Universidade Católica do Rio de Janeiro.

\section{Sites consultados:}

http://www.extra.globo.com http://www.fucandoatv.webnode.com http://www.logado.info http://www.minhaserie.com.br http://www.oglobo.globo.com http://www.patriciakogut.com http://www.privusbrasil.blogspot.com http://www.tvcontato.wordpress.com 